\title{
Comparison between Performance of Okra Waste and Wheat Bran for Removing some Heavy Metals from Wastewater
}

\author{
Karim Khalifa Esgair \\ Chemical Ind. Dep., Al-Technology Institute/Baghdad \\ Middle Technical University, Baghdad, IRAQ \\ E-mail: karimkhalifa70@yahoo.com \\ Received: 19-June-2017 Revised: 02-Oct.-2017 Accepted: 05-Nov.-2017
}

http://doi.org/10.29194/NJES21010036

\begin{abstract}
In the present work, the agricultural wastes which are wheat bran and raw okra waste used as adsorbent material for adsorption of cadmium and copper ions from wastewater. The effect of adsorption variable which include initial $\mathrm{pH}$ of solution, agitation speed, agitation time, initial concentration of cadmium and copper ions, and amount of adsorbent material were investigated in a batch process in order to obtain the maximum ions removal from wastewater .The results obtained from experimental investigation show that the percentage removal of metal ions increases with increasing $\mathrm{pH}$ and agitation speed until a maximize value after that it decreased with increasing $\mathrm{pH}$ and agitation speed. Also increases with increasing amount of adsorbent material and agitation time until a maximize value then reach a constant value approximately, and decreasing with increasing metal ions concentration .The maximum removal percent of cadmium and copper ions were $85.8 \%$ and $52.7 \%$ respectively which obtained at $\mathrm{pH}$ equal 5.0, agitation speed 150 revolution per minute, agitation time 105 minute , metal ion concentration $40 \mathrm{mg} / \mathrm{L}$, and adsorbent amount $1.5 \mathrm{gm}$ when using wheat bran as adsorbent material ,while obtained the maximum removal percent of cadmium and copper ions were $81.7 \%$ and $47.8 \%$ which obtained at $\mathrm{pH}$ equal 6.0 , and $\mathrm{pH}$ equal 5.0 respectively, agitation speed 150 revolution per minute, agitation time 90 minute ,metal ion concentration $40 \mathrm{mg} / \mathrm{L}$, and adsorbent amount $1.5 \mathrm{gm}$ when using okra waste as adsorbent material. From above result the wheat bran and okra waste was a best adsorbent material for removal cadmium and copper ions from wastewater but wheat bran slightly more effective than okra waste.
\end{abstract}

Keywords: Okra waste, wheat bran .heavy metal, wastewater, adsorption

\section{Introduction}

Environmental pollution is one of main problem facing by the humanity. A hazardous environmental problem produces from water pollution and attractive universal worry everywhere from the world, which increasing offensive and extent a maximum level that can be regarded a harmful to animals, plants and humans $[1,2]$

There are a numerous industries dispose heavy metal to wastewater such as battery industries , plating of metal ,tanneries , smelting the production of ceramic and glass, alloy industries, radiator manufacturing ,ammunition plastics, mining, , agrochemicals, petrochemicals, paint and pigment production, etc [3.4].The byproduct of these industries have many heavy metals such as lead, nickel, mercury, cadmium, copper and chromium which are nonbiodegradable and resort to accumulated in living creatures causes many disorders and diseases. wherefore a heavy metal must extracted to a terminal allowable concentration before discharging to environmental due to a very low concentration are toxic [5, 6].

Various method process have been used for elimination a heavy metal from wastewater before disposal drain to environmental surrounding, which mainly include membrane processes, ion exchange, solvent extracted , evaporation ,electrocoagulation , reverse osmosis, chemical precipitation, ,adsorption on activated carbon and biological materials $[7,8]$.In general the most of available process have disadvantages which are very expensive, difficulty used on widely scale application, technically complex ,used for wastewater treatment in specific cases ,and production a huge quantity of toxic sludge that needs for the additional treatment $[9,10]$.

Adsorption technique is recently process method used to remove a heavy metal from industrial wastewater. The one of common adsorbent used in adsorption process is activated carbon due to an affective adsorbent; the surface area and adsorption capacity are very high. This process is a very high cost due to the requirement regeneration after each adsorption process, its regeneration expensive and difficult which gives a limitation to use it's in different application of wastewater treatment. So that to reduce the cost of wastewater treatment many researchers attempted to seek the low cost and effective material for adsorption process.[11]

Agricultural wastes are used for extracting and recapturing of heavy metal from different 
wastewater as a natural material, abundant availability, and industrial by-product, inexpensive and effective adsorbent material, furthermore little generate a dangerous disposal problem. Numerous biological material such as wheat bran, rice husk, sawdust, okra waste, spent tea leaves, peanut husk, orange peels,...etc, which are basically formed of principal formation of cellulose, starch, lignin .lipids ,proteins and hemicelluloses that produce an affective adsorbent for a heavy metal and other pollutant . The functional groups like the carboxyl, phenol, methoxyl and hydroxyl it is the based composition of agricultural wastes, which may be treated chemically and physically for increasing the adsorption capacities to the heavy metal ions.(12,13 14)

Wheat and okra is one of the most crops produced and consumed in Iraq throughout the year. Okra is considered one of the most popular foods where most people eat it in different seasons. Wheat is grown and produced in large quantities where it is eat in different formulas. Therefore, the waste produced from these crops will be used to remove some heavy metals from industrial wastewater as locally available adsorbed materials.

The aim of present work is comparing performance between wheat bran and okra waste for the removal of cadmium and copper ions from wastewater. The effect of initial pH of aqueous solution, shaking speed, shaking time ,amount adsorbed material , and the initial concentration cadmium and copper ions on the removal percent of cadmium and copper ions have been investigated as a basis of comparison.

\section{Experimental work}

\subsection{Raw material collection and preparation.}

The wheat bran (wheat husks) was obtained as a by-product of household uses for preparing bread from flour and okra waste was obtained as a useless byproduct of the preparation of okra as a usual meal for most families. It's used to prepare the adsorbent material. The samples were washed with distilled water four times to remove the impurities. After that, the wheat bran and the okra waste were individually filtered and placed in an electrical oven at $50{ }^{\circ} \mathrm{C}$ for 24 hours with flipping from time to time for drying. The dried sample milling by laboratory electrical miller and sieved into particle size 250 micrometer for both wheat bran and okra waste.

\subsection{Fourier transforms infrared spectroscopy (FT-IR)}

The wheat bran and okra waste test was done to observe frequencies have been assigned. The FT-IR applied to observe presence or absence of effective group on the external surface of wheat bran and okra waste which registered in the region 400-4000 $\mathrm{cm}^{-1}$. This was achieved using Shimadzu FTIR 8400S type

\subsection{Chemical materials .}

The cadmium and copper ions aqueous solution were obtained from analytical grade of cadmium nitrate $\mathrm{Cd}\left(\mathrm{NO}_{3}\right)_{2} \cdot 4 \mathrm{H}_{2} \mathrm{O}$ and copper sulfate $\mathrm{CuSO}_{4} .5 \mathrm{H}_{2} \mathrm{O}$ respectively , which dissolved in de -ionized water to produce aqueous solution containing $1000 \mathrm{mg} / \mathrm{L}$ for each metal ions . This is achieved by dissolving 2.75 gm from cadmium nitrate $\left(\mathrm{Cd}\left(\mathrm{NO}_{3}\right)_{2} \cdot 4 \mathrm{H}_{2} \mathrm{O}\right)$ and 3.92 gm from copper sulfate $\left(\mathrm{CuSO}_{4} .5 \mathrm{H}_{2} \mathrm{O}\right)$ in one liter of de -ionized for each compound individually. This concentration dilute by de ionized water to obtain the required concentration

\subsection{The concentration of cadmium ion and} copper ion determination.

The variation of cadmium ion and copper ion concentration due to adsorbed by wheat bran and okra waste were determined by atomic absorption spectrophotometer (AAS). The percent removal of cadmium ion and copper ion $\left(Y_{R}\right)$ due to adsorption process was calculated according the equation:

$Y_{R}=\frac{C_{o}-C_{e}}{C_{o}} \times 100$

Where $\mathrm{Co}$ and $\mathrm{C}_{\mathrm{e}}$ represent the initial and equipoise concentration of cadmium ion and copper ion respectively.

\subsection{Investigation of process variable.}

The influence of five variables was studying which include, The $\mathrm{pH}$ of aqueous solution was adjusted between 2.0 and 8.0 by the addition of $0.1 \mathrm{M}$ of hydrochloric acid or $0.1 \mathrm{M}$ sodium hydroxide solutions, the agitation was changed from 50 to 250 revolution per minute. The variation of cadmium and copper ion concentration 20,40,60, and $80 \mathrm{mg} / \mathrm{L}$ were obtained by suitable dilution of original concentration $1000 \mathrm{mg} / \mathrm{l}$ by dilute with de ionized water. Varying agitation times of 15,30,45,60 75, 90, 105, and $120 \mathrm{~min}$, and the amount of wheat bran and okra waste was varied 0.5, $1.01 .5,2.0$, and $2.5 \mathrm{~g}$.

To study the influence of any one of above variable on the removal percent ,that variable has been varied gradually while keeping the other variable constant to obtained the maximize removal percent of cadmium and copper ions by wheat bran and okra waste. This is achieved by preparation of $50 \mathrm{ml}$ from heavy metal solution in conical flasks with suitable initial concentration and $\mathrm{pH}$ then added appropriate amount of adsorbed material. After that the conical flasks agitated by electrical shaker with certain agitation speed for fitting time. At the end of adsorption process the content of conical flasks were filtrated 
and the filtrate was analyzed by using a atomic absorption spectrophotometer to determine the equilibrium concentration of cadmium and copper ions.

\section{Result and Discussion}

\subsection{FTIR of wheat bran and okra waste}

FTIR test exhibit better information on the quality of functional groups available into the surface of wheat bran and okra waste. Abundant of functional groups have been definite an effective adsorbed site for binding a heavy metal .IR spectra of wheat bran and okra waste were shown in figures 1 and 2 . Wheat bran IR spectrum (figure 1) exhibit several intense bands. The band at 3398.57 was imputed to the surface hydroxyl groups $(-\mathrm{OH})$ and chemisorbed water . The band 3059.1 was attributed to amino groups $(\mathrm{N}-\mathrm{H})$. The bands at 2927 and 2897 can be assigned to the surface $\mathrm{C}-\mathrm{H}$ stretches of methylene groups and to chelated H-bridges . The bands at 1728.22, 1712.79, and 1666.5 were attributed to $\mathrm{C}=\mathrm{O}$ stretching, aromatic ring and amino stretching respectively. The band observed with small peaks 1550.77, 1519.91,1454 to 1130.29 can be assigned carboxylate groups. The band 1076.28 was attributed to phosphate groups. The bands 752.24, 709.8 ., 487.35,447.49 can be assigned to alumni (Al-O).silicate (Si-O-Ca),(Si$\mathrm{O})$ and ferro $(\mathrm{Fe}-\mathrm{O})$ groups respectively . Figure 2 gives the infrared spectrum of okra waste. This spectrum exhibit several bands. The band 3383.14 was attributed to the surface hydroxyl groups ($\mathrm{OH})$. The band 3059.1 was imputed to amino groups $(\mathrm{N}-\mathrm{H})$. The bands at $1647.21,1635$ can be assigned to carboxyl groups $\mathrm{C}=\mathrm{O}$, and $\mathrm{C}-\mathrm{O}$ C) respectively. The band 1072.42 was attributed to C-O groups. The band 632 can be assigned MO. The cadmium and copper ions were positive charge, while functional groups present in wheat and okra waste were negative charge due to a pair electrons on oxygen and nitrogen atoms. Wherefore the cadmium and copper ions adsorbed on functional groups present in wheat and okra waste due to the different in the charges between them, subsequently removed from wastewater.

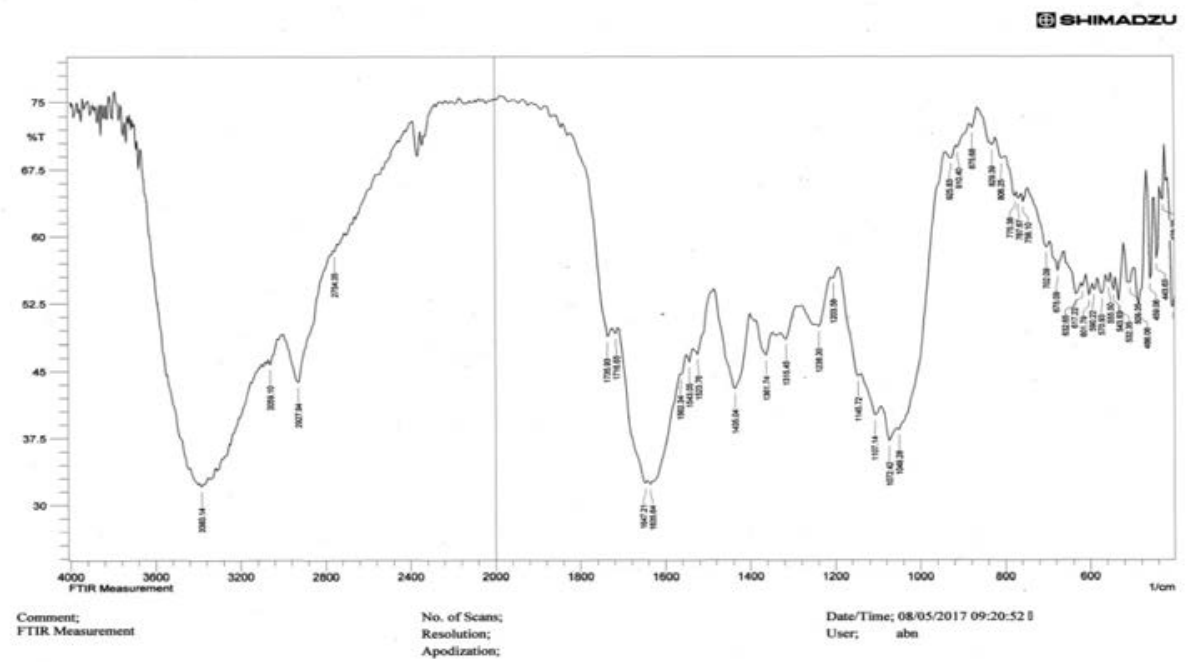

Figure 1: FTIR of wheat bran

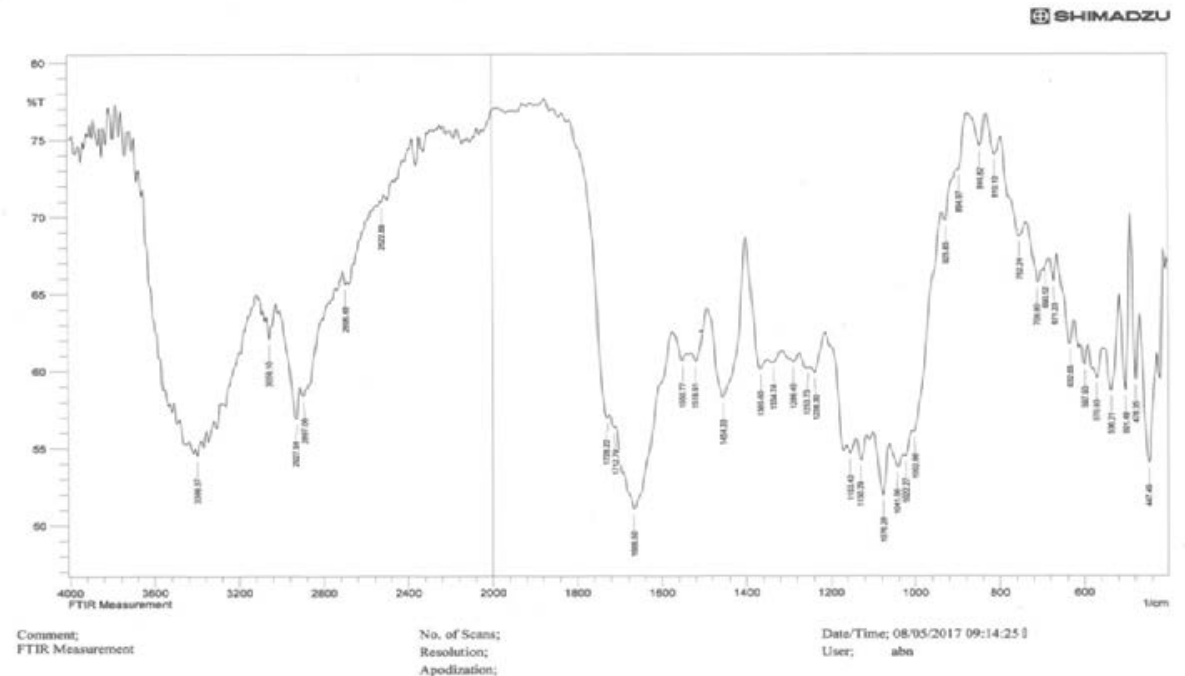

Figure 2: FTIR of okra waste 


\subsection{Influence of $\mathrm{pH}$}

The adsorption of cadmium and copper ions from the waste water solution was investigated at room temperature by changing the initial $\mathrm{pH}$ of solution from 2.0 to 8.0 . Initial $\mathrm{pH}$ values are considered the main factors affecting the adsorption capacity of cadmium and copper ions on agricultural wastes, including wheat bran and okra waste. Figs. 3 and 4 shows the effect of initial $\mathrm{pH}$ of wastewater on the removal percentage of cadmium and copper ions by wheat bran and okra waste. From these figures can be seen that the removal percentage expressing in terms of the cadmium and copper ions removal percent increased significantly with increasing the initial $\mathrm{pH}$ of the solution to reach a maximum value. When using wheat bran the results showed that the removal percent of cadmium was 26.8 at $\mathrm{pH} 2.0$ and increased to 65.4 at $\mathrm{pH}$ 5.0. For copper, the removal percent was 8.6 at $\mathrm{pH} 2.0$ and increased to 33.6 at $\mathrm{pH}$ 5.0. In the use of okra waste, the cadmium removal percent was 20.2 at pH 2.0 and increased to 53.5 at $\mathrm{pH} 6.0$.

For copper, the removal percent was 7.6 at $\mathrm{pH}$ 2.0- and increased to 29.2 at $\mathrm{pH}$ 5.0. After that the removal percent of cadmium and copper ions is relatively low with increasing the initial $\mathrm{pH}$ due to the competition adsorption between hydrogen ion and cadmium and copper ions on the active centers located in wheat bran and okra waste. Therefore, the initial $\mathrm{pH} 5.0$ will be selected for the next experiments to remove cadmium and copper ions from wastewater by using wheat bran. In addition, will be selected initial $\mathrm{pH} 5.0$ to remove copper and initial $\mathrm{pH} 6.0$ to remove cadmium from waste water using the okra waste as adsorbed material. Singha and Guleria found the ultimate removal of cadmium and copper appeared at $\mathrm{pH}$ range from 5.0 to7.0 by using okra waste[5] .

Nouri and Hamdaoui found the maximum removal of cadmium appeared at $\mathrm{pH} 5.0$ by using wheat bran [15], while the maximum removal of copper appeared at $\mathrm{pH} 5.0$ by using wheat bran its found by Wang et al. [16].

\subsection{Influence of agitation speed.}

The influence of agitation speed on the removal percent of cadmium and copper ions by wheat bran and okra waste were investigated at variant agitation speed from 50 to 250 revolution per minute and the results offered in figures 5 and 6 . The experimental results appear that the removal percent of cadmium and copper ions increased with increase shaking speed to extent maximum value. For cadmium and copper ions the removal percent was 55.6 and 25.5 at 50 strokes per minute and increased to 71.2 and 39.2 respectively at 150 strokes per minute when using wheat bran, while the removal percent of cadmium and copper ions was 45.8 and 23.4 at 50 revolution per minute and increased to 59.6 and 34.7 respectively at 150 revolution per minute when using okra waste.

This phenomenon may be explained as a follow: the increased of agitation speed increases the mobility of cadmium and copper ions which causes increases the diffusion coefficients subsequently increase the mass transfer rate of cadmium and copper ions to the surface of wheat bran and okra waste which increases the removal percent with increasing shaking speed. After that the increasing of shaking speed from 150 to 200 revolution per minute the removal percent decreased due to the fracturing of the bonding between the cadmium and copper ions and the surface site of wheat bran or okra waste which causes desorbing the cadmium and copper ions from surface site. An enhanced the probably physical adsorption is occurs rather than chemical adsorption. However, the shaking speed 150 revolution per minute will be selected for the next experiments to remove cadmium and copper ions from wastewater by using wheat bran and okra waste.

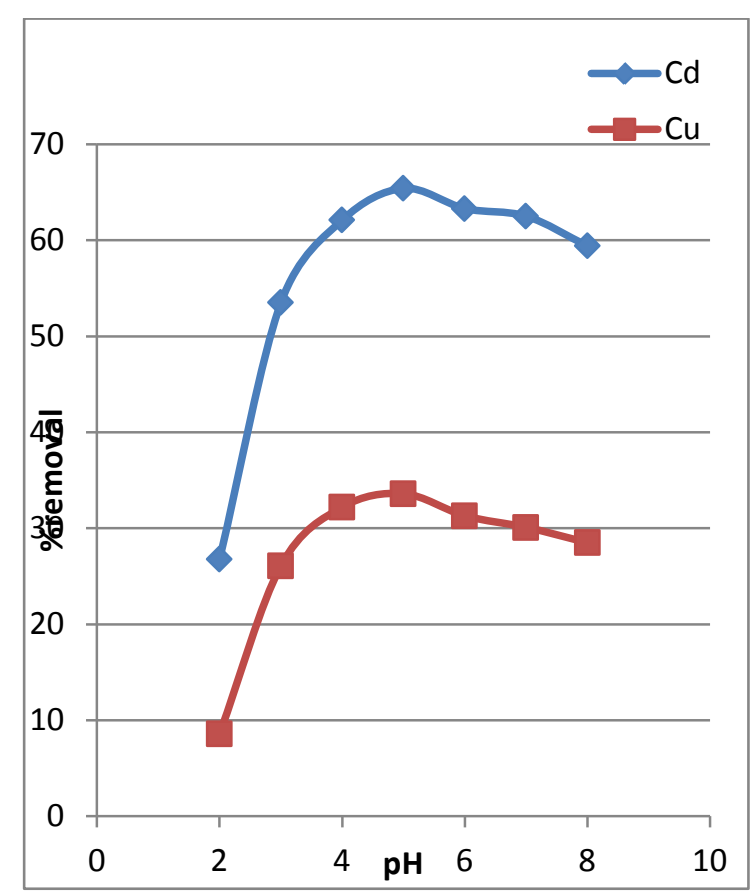

Figure 3: The influence of $\mathrm{pH}$ alteration on the removal percent of $\mathrm{Cd}(\mathrm{II})$ and $\mathrm{Cu}(\mathrm{II})$ by wheat bran [agitation speed $=100 \mathrm{rpm}, \mathrm{t}=120 \mathrm{~min}$, $\left.\mathrm{C}_{\mathrm{o}}=40 \mathrm{mg} / \mathrm{l}, \mathrm{d}=0.5 \mathrm{~g}\right]$ 


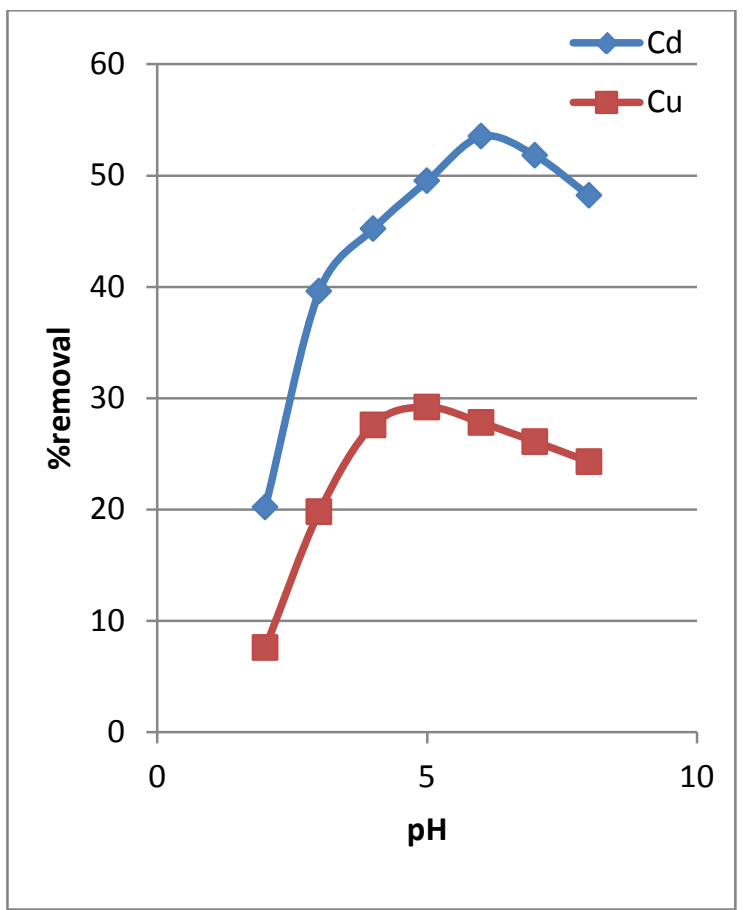

Figure 4: The influence of $\mathrm{pH}$ alteration on the removal percent of $\mathrm{Cd}(\mathrm{II})$ and $\mathrm{Cu}(\mathrm{II})$ by okra waste [agitation speed $=100 \mathrm{rpm}, \mathrm{t}=120 \mathrm{~min}$ ], $\left.\mathrm{C}_{\mathrm{o}}=40 \mathrm{mg} / \mathrm{l}, \mathrm{d}=0.5 \mathrm{~g}\right]$

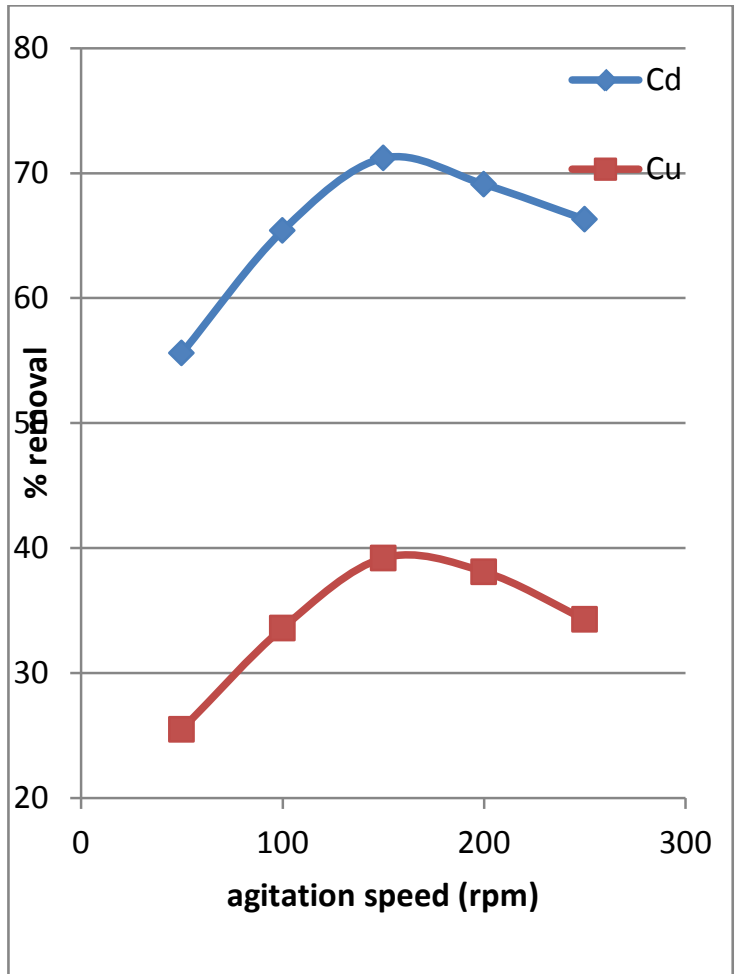

Figure 5: The influence of agitation speed on the removal percent of $\mathrm{Cd}(\mathrm{II})$ and $\mathrm{Cu}(\mathrm{II})$ by wheat bran $\left[\mathrm{pH}=5, \mathrm{t}=120 \mathrm{~min}, \mathrm{C}_{0}=40 \mathrm{mg} / \mathrm{l}, \mathrm{d}=\right.$ $0.5 \mathrm{~g}]$

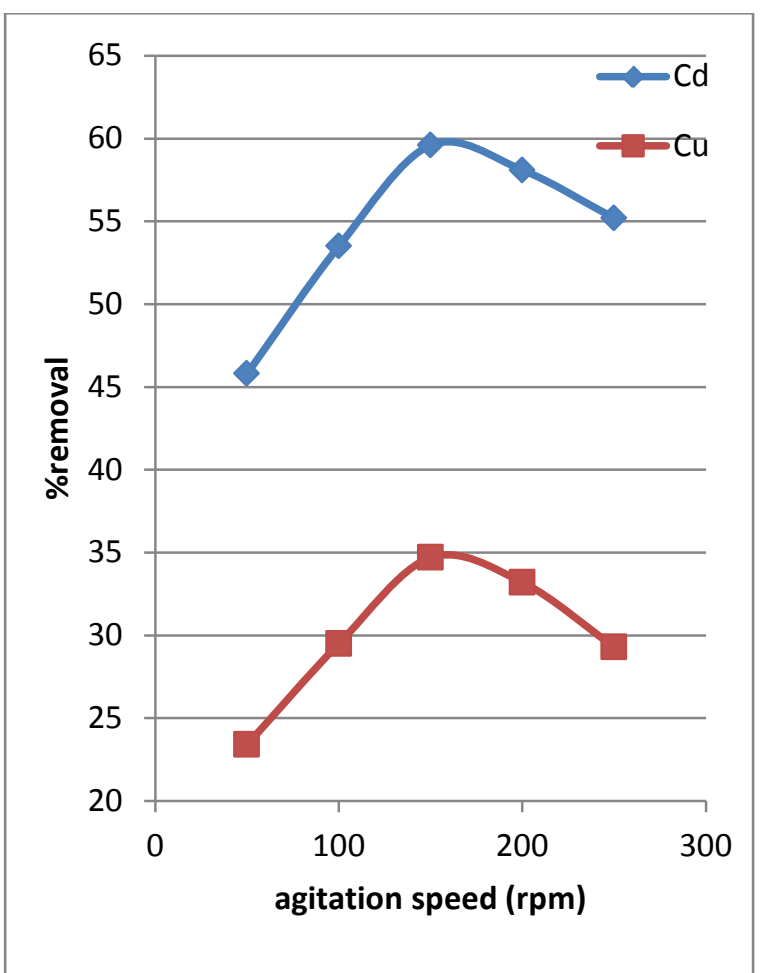

Figure 6: The influence of agitation speed alteration on the removal percent of $\mathrm{Cd}(\mathrm{II})$ and $\mathrm{Cu}(\mathrm{II})$ by okra waste $[\mathrm{pH}=6$ for $\mathrm{Cd}(\mathrm{II}), \mathrm{pH}=5$ for $\left.\mathrm{Cu}(\mathrm{II}) \mathrm{t}=120 \mathrm{~min}, \mathrm{C}_{\mathrm{o}}=40 \mathrm{mg} / \mathrm{l}, \mathrm{d}=0.5 \mathrm{~g}\right]$

\subsection{Effect of contact time}

The removal percent of cadmium and copper ions from waste water was investigated in adsorption batch process at different contact time from 15 to 120 minute .The relationship between removal percent of cadmium and copper ions and adsorbed time shows in figures 7and 8.These figures exhibit that the cadmium and copper ions removal increased with increasing the adsorbed time to reach a maximum value. That gives the cadmium removal percent was $71.2 \%$ at 105 min and the copper removal percent was $39.2 \%$ at 105 min using wheat bran, while the cadmium removal percent was 59.6 at 90 min and copper removal at 34.7 at 90 min using okra waste. After that the removal percent of cadmium and copper ions approximately was constant with increasing the agitation time due to access to the equilibrium state which occur when the saturation of the active centers and the inability to absorb more cadmium or copper ions . For this reason, the time of 105 minutes was chosen for the later experiments to remove cadmium and copper ions from waste water using wheat bran as adsorb material and 90 minute to remove cadmium and copper ions using okra waste as adsorbed material. Olabanji and Oluyemi study the removal of cadmium by using okra waste and found the best time is $120 \mathrm{~min}$ [17]. Singh et al study the removal of cadmium by using wheat bran and found the best time is $120 \mathrm{~min}$ [18]. 


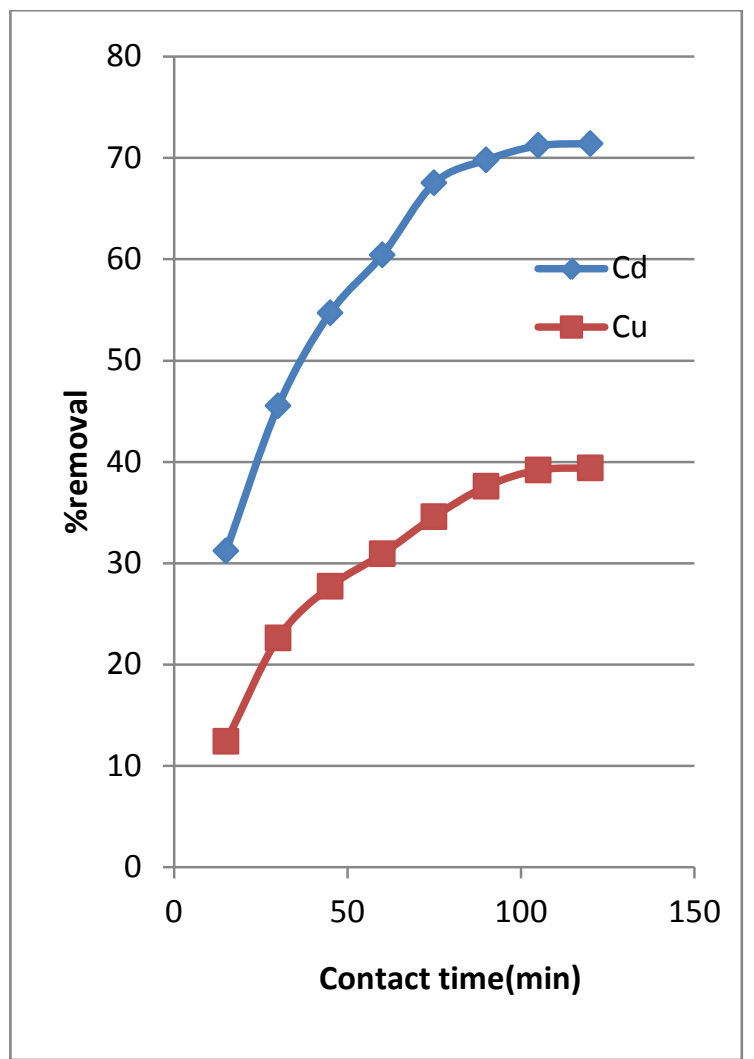

Figure 7: The effect of the contact time on the removal percent of , $\mathrm{Cd}(\mathrm{II})$ and $\mathrm{Cu}(\mathrm{II})$ by wheat bran $[\mathrm{pH}=5$ for $\mathrm{Cd}(\mathrm{II}), \mathrm{pH}=5$ for $\mathrm{Cu}(\mathrm{II})$, agitation speed=150 rpm , $\mathrm{C}_{0}=40 \mathrm{mg} / \mathrm{l}, \mathrm{d}=0.5 \mathrm{~g}$ ]

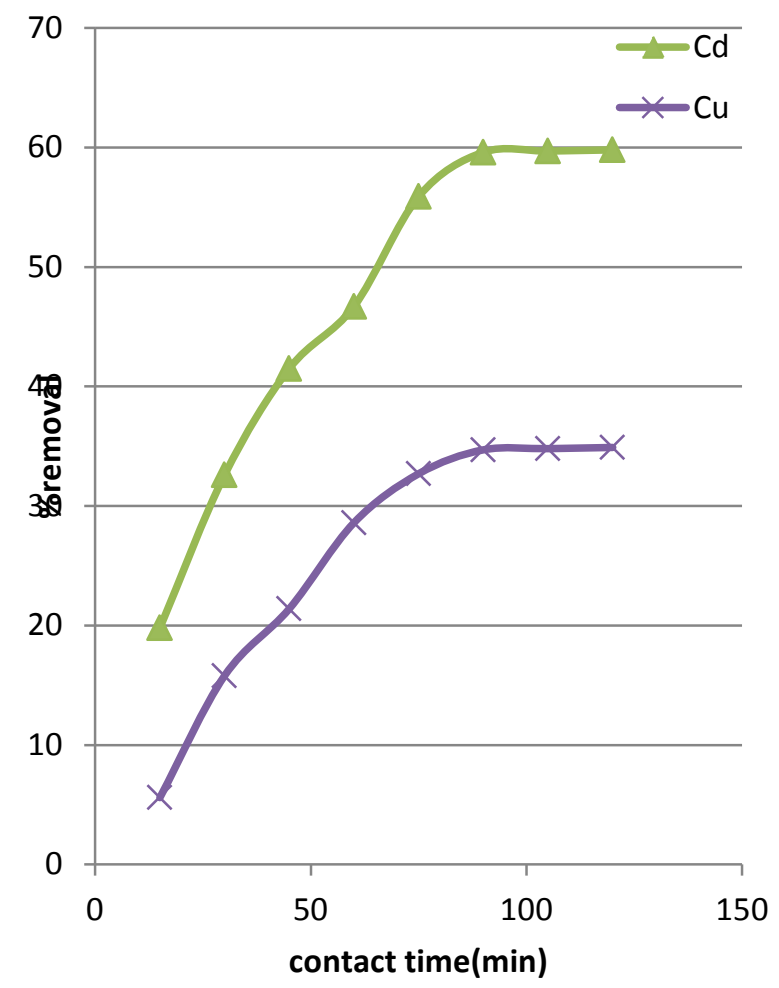

Figure 8: The effect of the contact time on the removal percent of, $\mathrm{Cd}(\mathrm{II})$ and $\mathrm{Cu}(\mathrm{II})$ by okra waste $[\mathrm{pH}=6$ for $\mathrm{Cd}(\mathrm{II}), \mathrm{pH}=5$ for $\mathrm{Cu}(\mathrm{II})$, agitation speed $\left.=150 \mathrm{rpm}, \mathrm{C}_{\mathrm{o}}=40 \mathrm{mg} / \mathrm{l}, \mathrm{d}=0.5 \mathrm{~g}\right]$

\subsection{Influence the initial concentration of cadmium and copper ions.}

The influence of the initial cadmium and copper ions concentration on the removal percent was examined at variant concentrations between 20 and $80 \mathrm{mg} / \mathrm{L}$ which were patronized by adsorption batch process, as shown in Figures 9and, 10. Experimental data indicate the removal percent of cadmium and copper decreased with increasing the initial cadmium and copper ions concentration. Removal percent of cadmium and copper ions decreased from $71.2 \%$ and $39.2 \%$ when the concentration $40 \mathrm{mg} / \mathrm{l}$ to $48.8 \%$ and $20.6 \%$ when the concentration $80 \mathrm{mg} / \mathrm{l}$ respectively with using wheat bran .while the removal percent of cadmium and copper ions decreased from $59.6 \%$ and $34.7 \%$ when the concentration $40 \mathrm{mg} / \mathrm{l}$ to $34.9 \%$ and $17.5 \%$ when the concentration $80 \mathrm{mg} / \mathrm{l}$ respectively with using okra waste. This result intend that the fact the removal percent of cadmium and copper ions strongly dependent on the initial concentration of cadmium and copper ions.

This may be imputation to the reality that for all stable changeable of experiments, the amount of adsorbed material also constant. When increasing the cadmium and copper ions concentration the removal percent decreased due to the number of available site for adsorb material becomes lowest in comparison with number of cadmium and copper ions, subsequently the removal percent the cadmium and copper ions decreased. Al-Barak and El-said study the removal of cadmium by using okra waste at concentration 20mg/L[19] . Olabanji and Oluyemi study the removal of cadmium by using okra waste at a concentration 200mg /L[17]. Singha and Guleria study the removal of cadmium and copper at a concentration from 100 to $1000 \mathrm{mg} / \mathrm{L}$ by using okra waste[5] . Ozer et al study the removal of copper at a concentration 100 $\mathrm{mg} / \mathrm{L}$ by using wheat bran [20].Dupont et.al study the removal of copper at a concentration from 10 to $250 \mathrm{mg} / \mathrm{L}$ by using wheat bran[21]. Singh et al study the removal of cadmium at a concentration from 10 to 15 mg/L by using wheat bran.[18] 


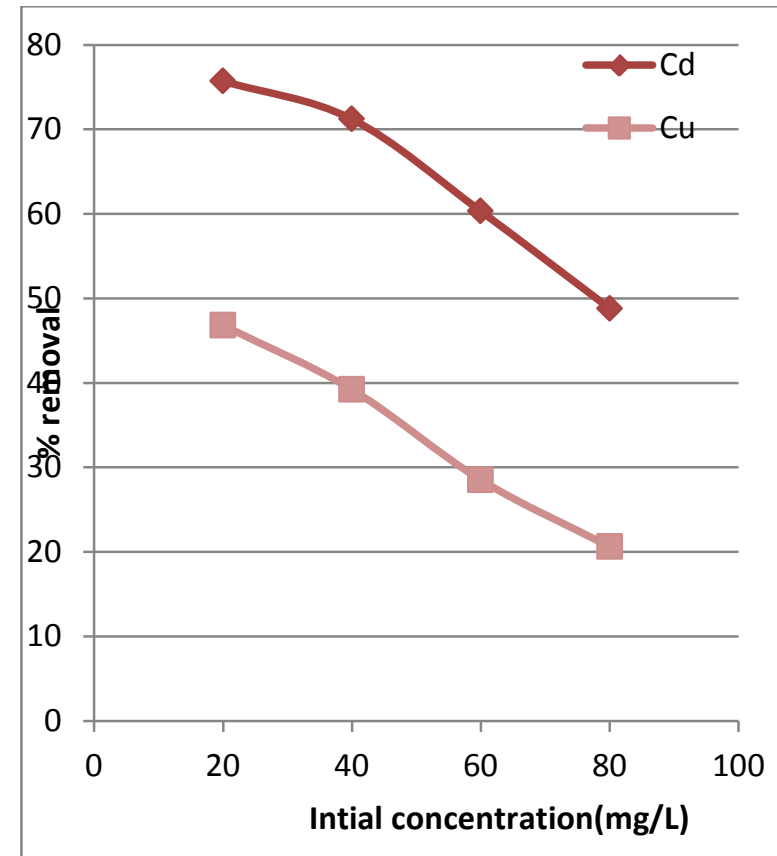

Figure 9: Effect of initial concentration of Cd(II) and $\mathrm{Cu}(\mathrm{II})$ on its removal percent by wheat bran $[\mathrm{pH}=5$ for $\mathrm{Cd}(\mathrm{II}), \mathrm{pH}=5$ forCu(II) , agitation speed $=150 \mathrm{rpm}, \mathrm{t}=105 \mathrm{~min}$ for $\mathrm{Cd}(\mathrm{II})$ and $\mathrm{Cu}(\mathrm{II}), \mathrm{d}=0.5 \mathrm{~g}]$

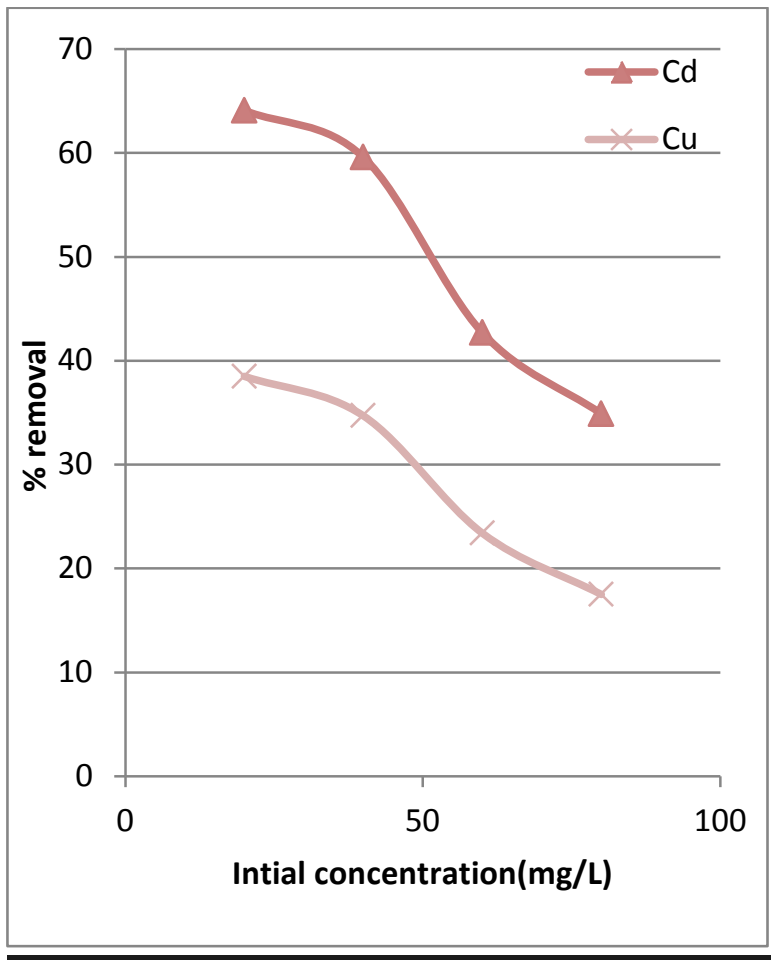

Figure 10: Effect of initial concentration of $\mathrm{Cd}(\mathrm{II})$ and $\mathrm{Cu}(\mathrm{II})$ on its removal percent by okra waste[pH= 6for $\mathrm{Cd}(\mathrm{II}), \mathrm{pH}=5$ for $\mathrm{Cu}(\mathrm{II})$, agitation speed=150 rpm,t=90 $\mathrm{min}$ for $\mathrm{Cd}(\mathrm{II})$ and $\mathrm{Cu}(\mathrm{II}), \mathrm{d}=0.5 \mathrm{~g}]$

\subsection{Influence of amount adsorbent}

The amount of adsorbent is an important factor which has a significant effect on the removal percent of heavy metals, including cadmium and copper from industrial wastewater by adsorption process. The removal percent of the cadmium and copper ions in constant of all the variables increases with increasing the amount of adsorbents this results exhibit in Figs 11 and 12 . These figures show that the removal percent of cadmium increased from71.2 to 85.8 percent and copper removal percent increase from 39.2 to 52.7 percent with increase the amount of wheat bran from $0.5 \mathrm{~g}$ to $1.5 \mathrm{~g}$, also the removal percent of cadmium increased from 59.6 to 81.7 percent and copper removal percent increase from 34.7 to 47.8 percent with increase the amount of okra waste from $0.5 \mathrm{~g}$ to $1.5 \mathrm{~g}$.

This result is due to the fact that increasing the amount of adsorbent material increases the surface area of its and thus increases the effective sites which has the ability to bind to the cadmium and copper ions, subsequently increasing their removal percent. Thereafter the increasing in the amount of absorbent material from $1.5 \mathrm{~g}$ to $2.5 \mathrm{~g}$, the removal percent of cadmium and copper remains approximately constant. This is due to the amount of adsorbable ions that have adsorbed, while non-adsorbable ions (free ions) do not absorb, so the removal percent remains approximately constant

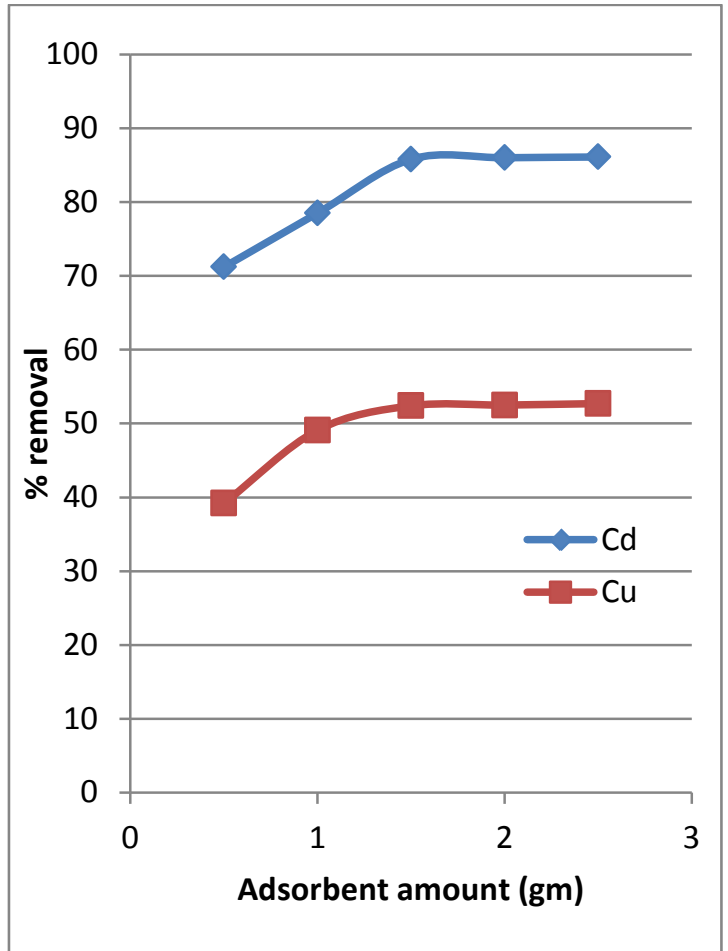

Figure 11: The effect of wheat bran amount on the removal percent of $\mathrm{Cd}(\mathrm{II})$ and $\mathrm{Cu}(\mathrm{II}) \mathrm{pH}=5$ for $\mathrm{Cd}(\mathrm{II}), \mathrm{pH}=5$ forCu(II), agitation speed $=150$ 
strokes per min, $\mathrm{t}=105 \mathrm{~min}$ for $\mathrm{Cd}(\mathrm{II})$ and $\mathrm{Cu}(\mathrm{II} \quad \mathrm{l}$ , $\left.40 \mathrm{mg} / \mathrm{C}_{0}=\mathrm{l}\right]$

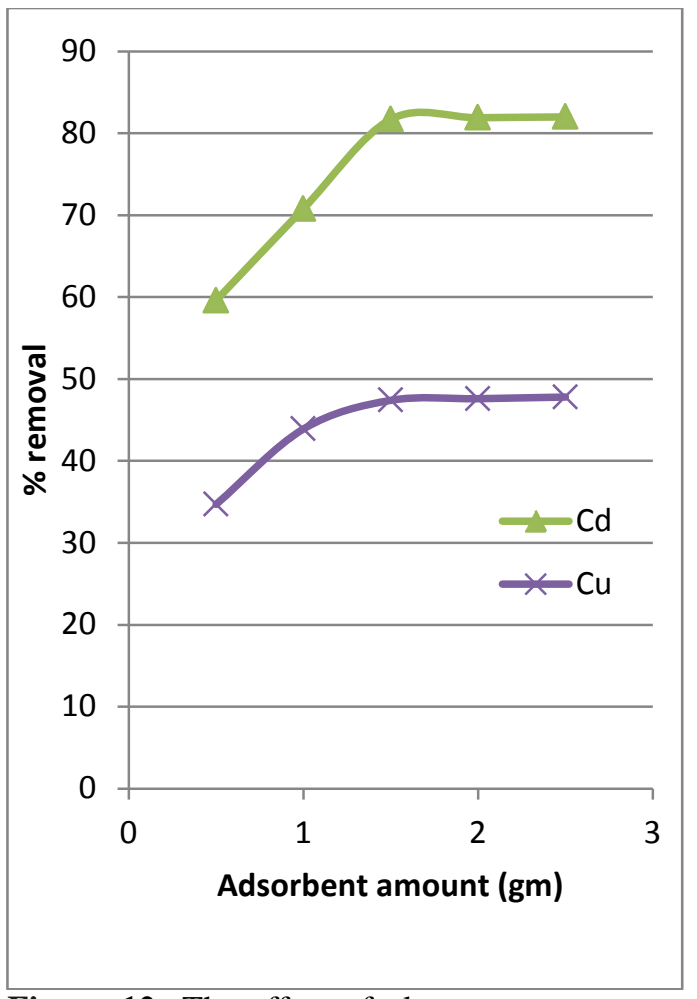

Figure 12: The effect of okra waste amount on the removal percent of ,Cd(II) and $\mathrm{Cu}(\mathrm{II})[\mathrm{pH}=6$ for $\mathrm{Cd}(\mathrm{II}), \quad \mathrm{pH}=5$ for $\mathrm{Cu}(\mathrm{II})$, agitation speed=150rpm,t=90 min for Cd(II) and Cu(II ), $\left.40 \mathrm{mg} / \mathrm{C}_{0}=\mathrm{l}\right]$

\section{Conclusion}

The obtained result appears that the wheat bran and okra waste an appropriate and an effective adsorbed material for removal cadmium and copper from wastewater. The percent removal of cadmium and copper ions was affected by initial $\mathrm{pH}$ of solution ,contact time ,initial cadmium and copper ions concentration, amount of adsorbed material . the best removal percent of cadmium and copper ions were $85.8 \%$ and 52.7 $\%$ respectively which obtained at agitation time 105minute, $\mathrm{pH}=5.0$ agitation speed $=150$ revolution per min, adsorbed amount $1.5 \mathrm{gm}$,and metal ion concentration $40 \mathrm{mg} / \mathrm{l}$ with using wheat bran as adsorbed material while the best removal percent of cadmium and copper ions were $81.7 \%$ and $47.8 \%$ respectively which obtained at metal ion concentration $40 \mathrm{mg} / \mathrm{L}$ adsorbed amount $1.5 \mathrm{gm}$, contact time 90 minute, and $\mathrm{pH}=5.0$, and $\mathrm{pH}=6.0$ respectively

\section{References}

[1] V. Saritha, Ch. Bavannarayana, ,Kkavitha,D,B,. “ Removal of pollutants in water using low cost materials" journal of global bioscience Vol.5 ,No.3, pp 3785-3793, 2016.
[2] R. Sudha, P.Premkumar "Lead Removal by Waste Organic Plant Source Materials Review" International Journal of ChemTech Research Vol.9, No. 1, pp 47-57, ,. 2016.

[3] J. Seniunait,R. Vaiškunait, V. Bolutien, "Coffee grounds as an adsorbent for copper and lead removal formaqueous solutions" The 9th International Conference "environmental engineering ”22-23 May, 2016,Vilnius, Lithuania.

[4] V. Bobade, C. Eshtiagi, "Heavy Metals Removal from Wastewater by Adsorption Process: A Review" APCChE Congress incorporating Chemeca 27 Sept - 01 Oct, 2015, Melbourne, Victoria.

[5] S.Singha, A,. Guleria, "Utility of chemically modified agricultural waste okra biomass for removal of toxic heavy metal ions from aqueous solution” Engineering in Agriculture, Environment and Food Vol. 8, pp 52-60,2015

[6] K. Dermentzis, A,Christoforidis, Valsamidou., E " Removal of nickel, copper, zinc and chromium from synthetic and industrial wastewater by electrocoagulation” I.J.E.S., Vol. 1, No 5,.pp 697-710,2011

[7] T,O Jimoh, ,, Y.A, Iyaka, , M.M. Nubaye, ,. " $\quad$ Sorption Study of Co (II), Cu(II) and $\mathrm{Pb}$ (II) ions Removal from Aqueous Solution by Adsorption on Flamboyant Flower (Delonix Regia” American Journal of Chemistry Vol. 2, No.3, pp. 165-170,2012

[8] A, M Etorki, ,.M. El-Rais, ,. M.Mahabbis, N, M Oussa, "Removal of Some Heavy Metals fromWastewater by Using of Fava Beans" American Journal of Analytical Chemistry,Vol., 5, pp 225-234,2014

[9] T.M. Alslaibi, I. Abustan, M.A. Ahmad, A. Abu Foul, "Cadmium removal from aqueous solution using microwaved olive stone activated carbon”, Journal of Environmental Chemical Engineering ,Vol.1,No.3, pp 589-599,2013

[10] M.A Baraka,. "New trends in removing heavy metals from industrial wastewater” Arabian Journal of Chemistry Vol. 4,pp 361-377,2011

[11] M.S Rajput, A.K. Sharma, S. Sharma, S. Verma , "Removal of lead (II) from aqueous solution using low cost abundantly available adsorbents: Areview" International Journal of Chemical Studies Vol.3, No.1,pp.9-14,2015

[12] O.E. Abdel Salam,N. Reiad , M.M ElShafei, "A study of the removal characteristics of heavy metals from wastewater by low-cost adsorbents" Journal of Advanced Research Vol. 2, pp.297-303,2011 
[13] J. Salehzaden, "Removal of Heavy Metals $\mathrm{Pb} 2+, \mathrm{Cu} 2+, \mathrm{Zn} 2+, \mathrm{Cd} 2+, \mathrm{Ni2}+, \mathrm{Co} 2+$ and $\mathrm{Fe} 3+$ from Aqueous Solutions by using Xanthium Pensylvanicum” Leonardo Journal of Sciences Issue 23, July-December p. 97104,2013

[14] M. Arbabi1,S. Hemati ,M. Amiri. "Removal of lead ions from industrial wastewater: A review of Removal methods" International Journal of Epidemiologic Research,Vol. 2,No. 2, pp105-109.,2015

[15] A.Singha, ,.A. Guleria,. "Utility of chemically modified agricultural waste okra biomass for removal of toxic heavy metal ions from aqueous solution" Engineering in Agriculture, Environment and Food .Vol. 8 ,pp5260,2015

[16] L. Nouri, O. Hamdaoui, “ Ultrasonication-assisted sorption of cadmium from aqueous phase by wheat bran”. J. Phys. Chem. A 111,pp. 8456-8463.2007

[17] X.S. Wang, Z.Z. Li, C. Sun,. “A comparative study of removal of $\mathrm{Cu}$ (II) from aqueous solutions by locally low-cost materials: marine macroalgae and agricultural by-products". Desalination Vol.235, pp146-159.2009
[18] O Olabanji. E. Oluyemi E. “Comparison of Effectiveness of Raw Okra (Abelmoschus esculentus L)and Raw Sugarcane (Saccharum officinarum) Wastes as Bioadsorbent of Heavy Metal in Aqueous”. Environment and Pollution; Vol. 4, No. 1; pp,1-8,2015

[19] K.K. Singh ,A.,.K. Singh, S.H „.. Hasan "Low cost bio-sorbent _wheat bran_ for the removal of cadmium from wastewater: Kinetic and equilibrium studies" Bioresource Technology Vol. 97 ,.pp.994-1001,2006

[20] A.B.S Al-Barak , S.M .and El-Said , “ The use of some food industrial by product for wastewater purification”. Research journal of environmental science, Vol 4.No .6 ,.pp 566572,2010

[21] A. Ozer, D., Ozer, A., Ozer, "The adsorption of copper (II) ions on to dehydrate wheat bran (DWB): determination of the equilibrium and thermodynamic parameters". Process Biochem. Vol.39,pp 2183-2191,2004

[22] L. Dupont, J., Bouanda, J., Dumonceau, M, Aplincourt,.. “ Biosorption of Cu(II)and Zn(II) onto a lignocellulosic substrate extracted from wheat bran”. Environ.Chem. Lett. Vol. 2,pp 165168,2005

\section{مقارنهة بين أداء نقايات البامية ونخالة القمح لإزالة بعض المعادن الثقيلة من مياه الصرف الصناعي \\ كريم خليفه ازغير الصغير

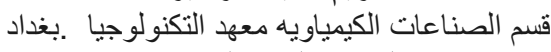

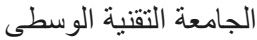

الخلاصه

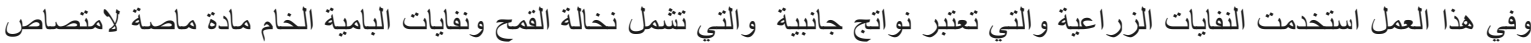

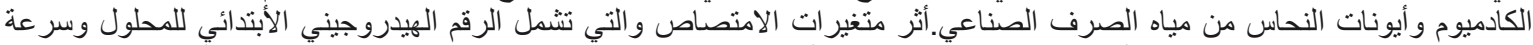

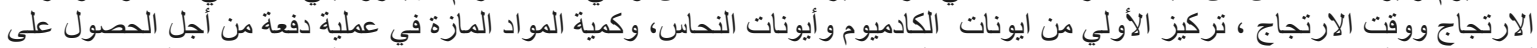

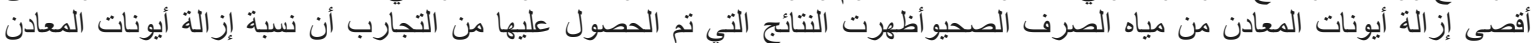

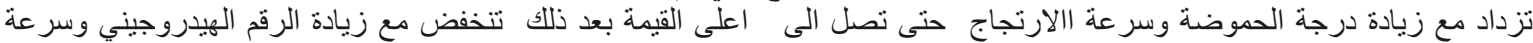

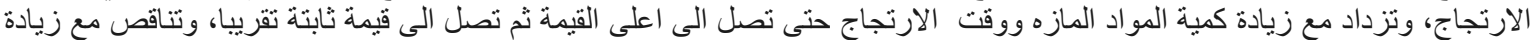

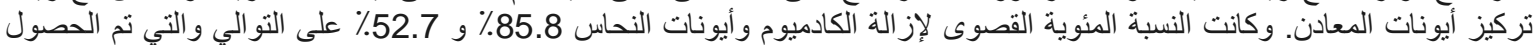

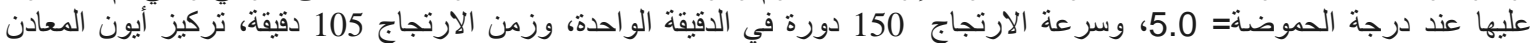

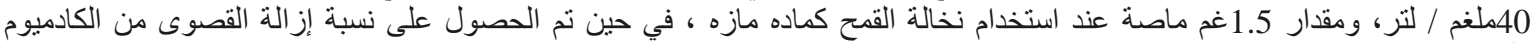

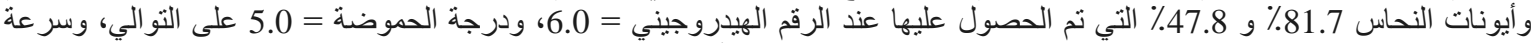

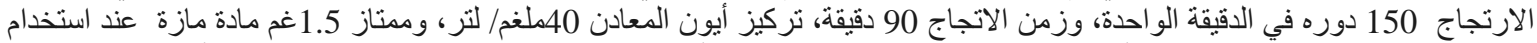

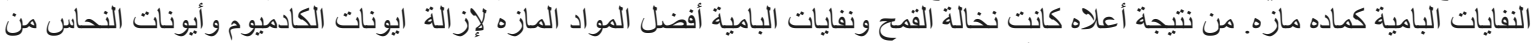
مياه الصرف الصحي ولكن نخالة القمح كانت أكثر فعالية من النفايات البامية نفانة 